\title{
Factors relating to circulating immune complexes in rheumatoid arthritis
}

\author{
P. J. ROBERTS-THOMSON, B. L. HAZLEMAN, ${ }^{*}$ I. G. BARNETT, \\ I. C. M. MACLENNAN, AND A. G. MOWAT
}

From the Nuffield Department of Clinical Medicine, Radcliffe Infirmary, and the Rheumatology Unit, Nuffield Orthopaedic Centre, Oxford

\begin{abstract}
Roberts-Thomson, P. J., Hazleman, B. L., Barnett, I. G., MacLennan, I. C. M., and Mowat, A. G. (1976). Annals of the Rheumatic Diseases, 35, 314-320. Factors relating to circulating immune complexes in rheumatoid arthritis. Evidence has been presented suggesting that circulating immune complexes occur in over half of the sera of patients with rheumatoid arthritis. These IgG-containing complexes were small, eluting between IgG and IgM on gel filtration on Sepharose 6B and were not seen in the sera of healthy control subjects. These complexes were detected in the sera of both seronegative and seropositive patients and their quantity did not correlate with IgM rheumatoid factor titre. The quantity of complexed IgG was estimated from a ratio derived from the IgG profile obtained by gel filtration of the serum. This quantity correlated significantly with the degree of inhibition by the rheumatoid sera of cytolysis in vitro of IgG sensitized target cells by $\mathrm{K}$ cells from human peripheral blood. A significant inverse correlation was observed between the quantity of serum complexes and the chemotactic index of the circulating polymorphonuclear leucocytes obtained from the same rheumatoid patient. It is suggested that ingestion of these complexes may be implicated in the reduction in chemotaxis observed in patients with rheumatoid arthritis. There was no correlation between the quantity of the complexes in the sera and other clinica:, haematological, and biochemical measurements.
\end{abstract}

The presence of circulating IgG complexes of small size (i.e. sedimenting between 7 and 19S) has now been shown in the sera of patients with a wide variety of diseases. These include rheumatoid arthritis and hypergammaglobulinaemic purpura of Waldenström (Kunkel and others, 1961), systemic lupus erythematosus and Sjøgren's syndrome (Blaylock, Waller, and Normansell, 1974; AlarconSegovia and others, 1974), inflammatory bowel disease (Jewell and MacLennan, 1973), and some thyroid disorders (Calder and others, 1974). The nature of these immune complexes and their relationship to the pathogenesis of these diseases is obscure. In rheumatoid arthritis small immune complexes are frequently found and are often present in considerable quantity (Winchester and others, 1971; Norberg, 1974).

In this study two techniques have been used to detect and quantitate small immune complexes in the sera of 35 patients with rheumatoid arthritis. The first technique involves the separation of serum IgG using Sepharose 6B column chromatography (Jewell and MacLennan, 1973). In this method complexed IgG separates in higher molecular size fractions than noncomplexed IgG. The second technique is a functional assay which can detect certain immune complexes and aggregates of IgG. This technique is based upon the principle that antibody-dependent cell-mediated cytotoxicity or $\mathrm{K}$ cell mediated cytotoxicity can be competitively inhibited by immune complexes occupying the receptors for antibody on $\mathrm{K}$ cells and so preventing $\mathrm{K}$ cell access to target cells sensitized with antibody.

A ratio derived from gel filtration chromatography has been described for estimating the amount of these complexes found circulating in the sera of 
our patients, and this quantity has been correlated with certain clinical, haematological, and biochemical features.

\section{Material and methods}

PATIENTS, CLINICAL AND BIOCHEMICAL ASSESSMENT, AND CONTROLS

Thirty-five patients with definite or classical rheumatoid arthritis were studied. 24 had a positive differential agglutination titre (1:32 or greater). All patients were receiving anti-inflammatory drugs, and in addition 11 patients were taking prednisone, mean dose $6.5 \mathrm{mg}$ (range 5-10 $\mathrm{mg}$ ); the dose had been stable for at least the preceding 3 months.

Clinical activity of the rheumatoid arthritis was assessed by the duration of morning stiffness and by an articular index (Camp, 1971). Laboratory investigations included measurements of the sedimentation rate (Westergren method), haemaglobin and total white cell count, blood urea and serum creatinine, total protein and albumin globulin ratio, the differential agglutination titre for rheumatoid factor, and antinuclear antibody.

Control sera were obtained from 18 healthy laboratory personnel.

\section{K CELL CYTOTOXICITY INHIBITION ASSAY}

Human blood lymphocytes from a single donor (I.C.M.M.) were used as the source of $K$ cells. The lymphocytes were separated from peripheral defibrinated blood by $3 \%$ gelatine sedimentation. The target cells were ${ }^{51} \mathrm{Cr}$ labelled Chang cells and were sensitized with 1:10 000 rabbit anti-Chang antibody (MacLennan, Loewi, and Howard, 1969).

Cultures of $0.3 \mathrm{ml}$ were set up as follows. The basic medium was HEPES buffered Eagle's basal medium enriched with $10 \%$ fetal bovine serum (Biocult Batch 00239). Each culture contained $2 \times 10^{4}$ sensitized target cells and $3 \times 10^{5}$ peripheral blood lymphocytes. The culture contained dilutions of patient's serum or control serum. Each experiment also included cultures containing the following two standards: (1) $500 \mu \mathrm{g}$ aggregated human IgG obtained from aliquots of a single batch. (2) Medium only, i.e. no inhibitor.

Test sera were diluted to final concentrations of $1: 3$. Cultures were incubated at $37^{\circ} \mathrm{C}$ for $3 \frac{1}{2}$ hours. After this time, $1 \mathrm{ml}$ of cold saline was added to each tube and the cultures were centrifuged at $200 \mathrm{~g}$ for 7 minutes. Exactly $1 \mathrm{ml}$ of supernatant was then removed from each tube, the residue and supernatant tubes counted on a Wallac gamma scintillation counter and the per cent ${ }^{51} \mathrm{Cr}$ release then calculated. Per cent inhibition was calculated as follows:

\footnotetext{
$\frac{\% \text { release in medium }-\% \text { release in test serum }}{\% \text { release in medium }-\% \text { release with aggregated } \mathrm{IgG}} \times 100$.
}

\section{GEL FILTRATION CHROMATOGRAPHY}

Fresh sera $(0.5 \mathrm{ml})$ were fractionated at $4^{\circ} \mathrm{C}$ on Sepharose $6 \mathrm{~B}$ (Pharmacia) columns $(40 \times 2.5 \mathrm{~cm})$ in phosphate buffered saline $\mathrm{pH} 7 \cdot 3$ with $0.02 \%$ sodium azide. Peristaltic pumping maintained an upward flow rate of $20 \mathrm{ml} / \mathrm{h} .3 \mathrm{ml}$ eluate fractions were collected and measured for their optical density (at $280 \mathrm{~m} \mu$ ). The fractions were then assayed for IgG. IgG commencement was defined as the elution volume where IgG was initially detected and is designated $c$ in Fig. $1 B$ for one representative serum.

It is known from animal experiments (Benacerraf, Sebestyen, and Cooper, 1959; Mannik and Arend, 1971) that immune complexes which persist in the circulation have small degrees of lattice formation, i.e. have 1-3 IgG molecules/antigen(s). Larger complexes are rapidly taken up by the reticuloendothelial system.

We have also observed that preformed immune complexes dissociate to some extent on gel filtration (due to dilution), the degree depending on the affinity of the antibody (Gotch, 1973). The IgG dissociating from this complex is still partially separated from noncomplexed IgG and can be found eluting in earlier fractions than seen for the noncomplexed IgG. But as the concentration of IgG in these early fractions is also dependent on the total noncomplexed monomeric IgG concentration it is necessary to take into account the total IgG concentration if the early eluting IgG is to be measured.

Thus in order to assess IgG which was or had been in the complexed form, a ratio derived from the IgG profile was established. This ratio was defined as the concentration of IgG measured at the monomeric IgG marker divided by the concentration of IgG at the point where two firmly bound molecules of IgG were calculated to elute. The dimeric IgG elution position (i.e. (IgG) Fig. $1 \mathrm{~A}$ ) was calculated from the graph where the elution position of a number of proteins were plotted against their known molecular weight. The monomeric to dimeric IgG ratio (M:D) is signified as b/a in Fig. $1 B$ and is taken as an index of the amount of complexed IgG present. In normal sera the concentration $a$ varied directly with the concentration $b$.

\section{POLYMORPHONUCLEAR LEUCOCYTE CHEMOTACTIC INDEX}

The chemotactic index of the polymorphonuclear leucocytes from 21 rheumatoid patients was measured using the method of Baum, Mowat, and Kirk (1971). In this method polymorphs are sedimented onto a restricted area of a $3 \mu \mathrm{m}$ millipore filter, which is placed in a standard tissue culture chamber. On the 'starting' side of this chamber is placed Hanks's solution and on the 'attractant' side a solution containing casein and complement. After incubation for 3 hours at $37^{\circ} \mathrm{C}$ the number of polymorphs on both sides of the filter are counted and the chemotactic index calculated from the ratio of the cells on the attractant side to the cells on the starting side.

\section{SERUM PROTEIN ESTIMATIONS}

The immunoglobulins $\mathbf{G}, \mathrm{A}$, and $\mathrm{M}$, haptoglobulins $(\mathrm{Hp})$, alpha $_{2}$ macroglobulin $\left(\alpha_{2} M\right)$ and albumin (Alb) were measured by the radial immunodiffusion method of Mancini, Carbonara, and Heremans (1965) using commercially available antisera.

\section{ANALYSIS OF RESULTS}

Many of the estimations could not be considered to be normally distributed and hence nonparametric statistical tests were used. The Wilcoxon sum of ranks test was used when comparing two groups. Correlation between variables within a group were performed using the Spearman rank correlation coefficients. 


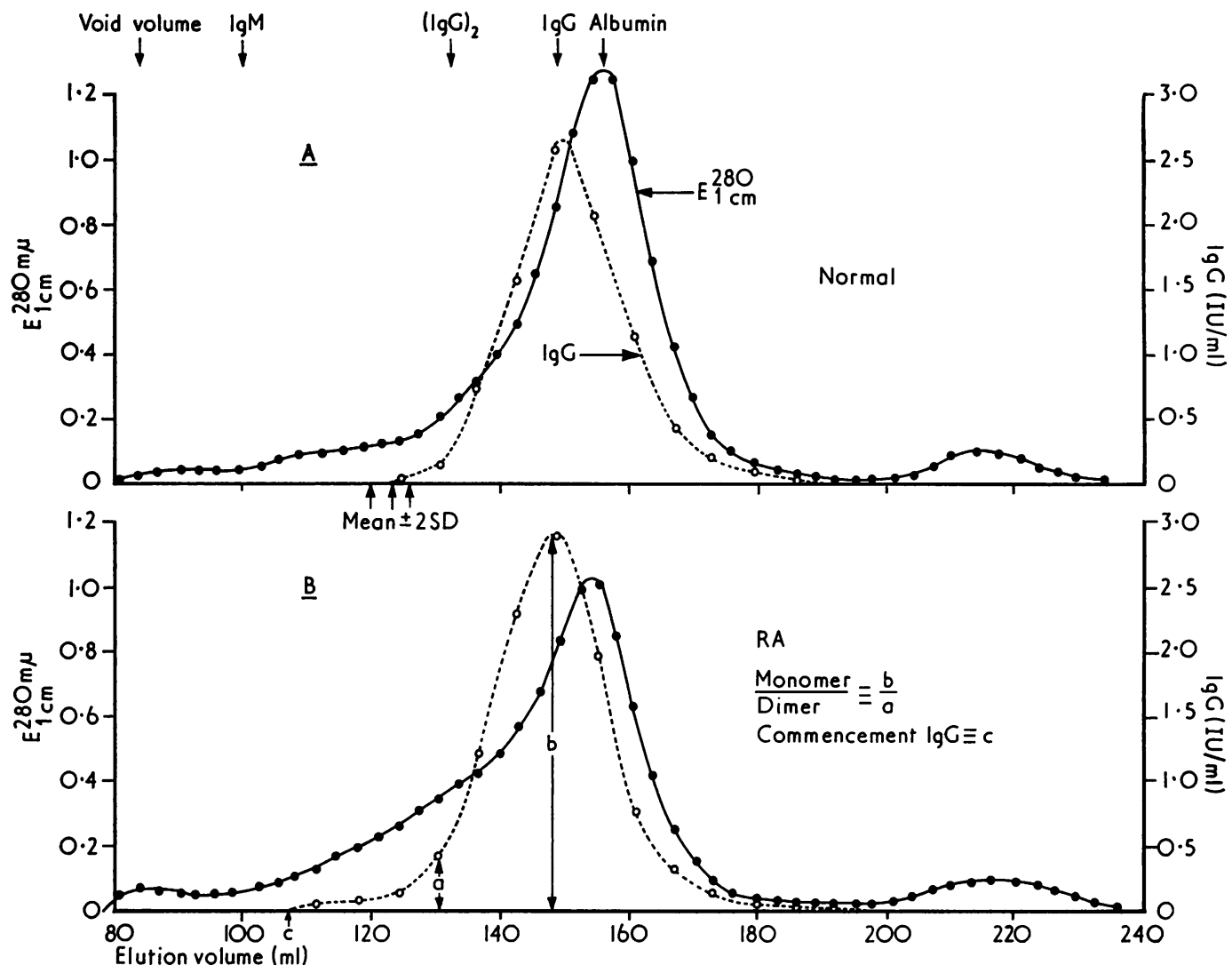

FIG. 1 Elution profiles obtained from gel chromatography of serum on Sepharose 6 B. A The continuous line signifies the optical density of the eluate read at $280 \mathrm{m \mu}$, while the broken line is the profile of $\mathrm{IgG}$ in $\mathrm{IU} / \mathrm{ml}$ estimated in the eluate fractions. Peak elution volumes for the calibration of the column for different marker proteins are shown. $(\mathrm{IgG})_{2}=$ elution volume where dimeric $\operatorname{IgG}$ is expected to peak. Commencement $\operatorname{IgG}(=C)$ is the volume where IgG is first detected. Mean $\pm 2 S D$ is shown for commencement IgG obtained from 18 sera from normal healthy subjects. B The monomer/ dimer ratio $\equiv(b / a)$ is the concentration of $I g G$ at peak monomeric IgG elution volume $(b)$ to concentration of IgG at peak dimeric IgG elution volume (a). The results obtained from a normal healthy subject (upper profiles) and that from a patient with rheumatoid arthritis (lower profiles) are shown for comparison.

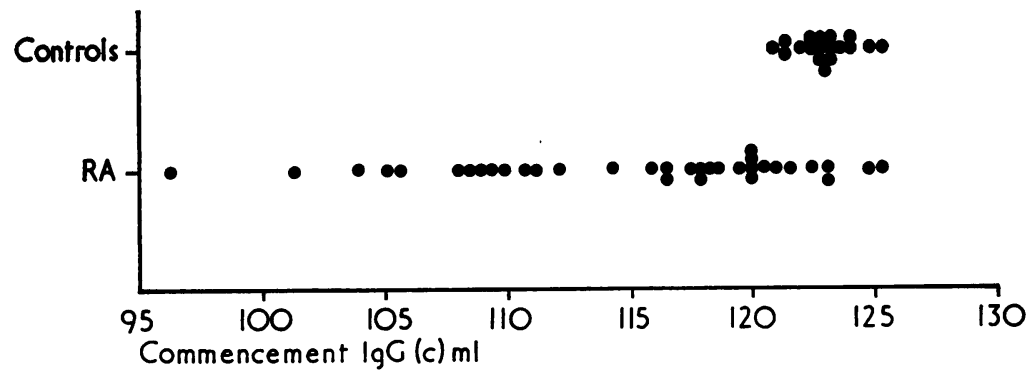

FIG. 2 Each point signifies the elution volume (commencement $\operatorname{Ig} G(c)$ ) where $\lg G$ was first detected in gel chromatography on Sepharose $6 B$ of serum obtained from $R A$ patients and healthy controls

\section{Results}

\section{ASSAYS FOR IMMUNE COMPLEX IN SERA}

(a) Sepharose $6 B$ filtration chromatography

Eighty per cent of the sera of 35 patients with rheumatoid arthritis had IgG separating in higher molecular size fractions than any of the 18 healthy controls (Fig. 2). Interestingly, 3 of the 8 patients with seronegative rheumatoid arthritis were shown to have complexed IgG.

The concentration of IgG at the monomer IgG position ( $b$ Fig. 1) was $2 \cdot 3 \pm 1 \cdot 1 \mathrm{IU} / \mathrm{ml}$ (mean \pm 
SD) for the rheumatoid group and $1.7 \pm 0.8 \mathrm{IU} / \mathrm{ml}$ (mean $\pm \mathrm{SD}$ ) for the control group. Since the monomer: dimer IgG ratio was significantly lower in the rheumatoid group (RA $<$ healthy controls, $\mathbf{P}<0.005$, Fig. 3) this indicates that the concentration of IgG at the dimeric IgG position $a$ is abnormally large in this group and suggests the presence of complexed IgG.

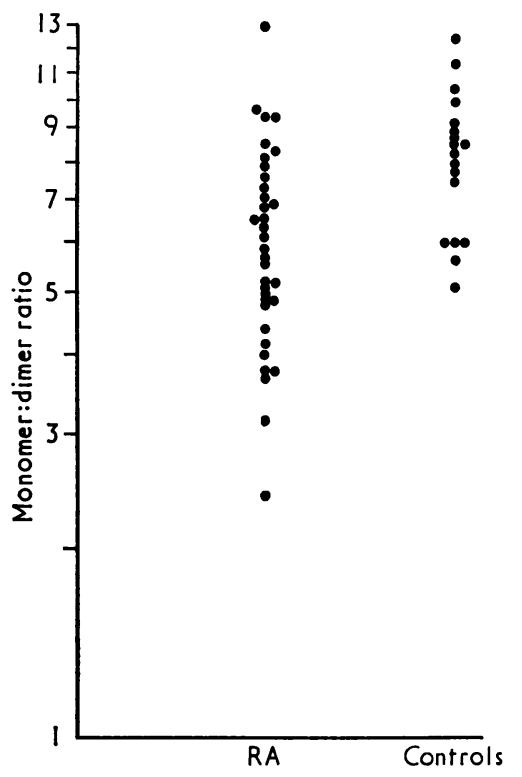

FIG. 3 Monomer:dimer ratios for $R A$ patients and controls

Comparison of IgG commencement values with monomer:dimer ratio in the rheumatoid group showed lack of correlation, $P=0 \cdot 779$. This, therefore, seems to provide evidence that these are measurements of two different variables, perhaps indicating two types of complex with distinct and independent origins.

\section{(b) $K$ cell cytotoxicity inhibition}

The results obtained with sera diluted $1: 3$ for the two groups are shown in Fig. 4. The rheumatoid arthritic group showed significantly greater inhibition than the healthy controls, $\mathrm{P}<\mathbf{0 . 0 0 5}$.

$\mathrm{K}$ cell cytotoxicity inhibition correlated strongly with the monomer: dimer ratio $(P=0.013)$ but not with IgG commencement $(P=0.963)$. No correlation was seen between the assays for complexes and IgM rheumatoid factor titre and the results obtained from the two assays did not directly correlate with serum IgG levels. In fact an inverse correlation was observed between $\%$ inhibition of cytotoxicity and serum IgG concentration $(P=$ 0.009).
POLYMORPHONUCLEAR LEUCOCYTE CHEMOTAXIS

It has previously been suggested that impairment in neutrophil chemotaxis in patients with RA may be related to the prior ingestion of immune complexes (Mowat and Baum, 1971). The mean value for the chemotactic index for the 21 patients in the rheumatoid group studied was 417 with a range of 166 to 601 . (Mean \pm ISD for healthy adults is $553 \pm 69$; Mowat and Baum, 1971). A significant correlation was observed between the neutrophil chemotactic index and the serum monomer: dimer ratio for these rheumatoid patients $(0.02<\mathrm{P}<0.05)$ (Fig. 5).

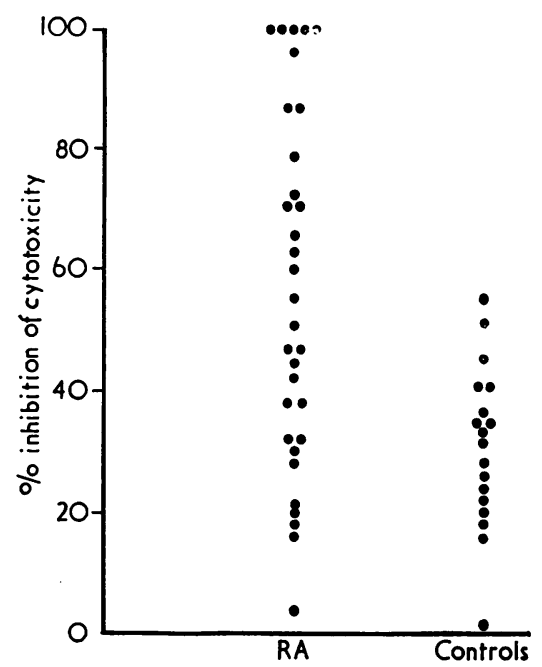

FIG. 4 Per cent cytotoxicity inhibition by sera of antibody-dependent $K$ cell induced target cell cytolysis

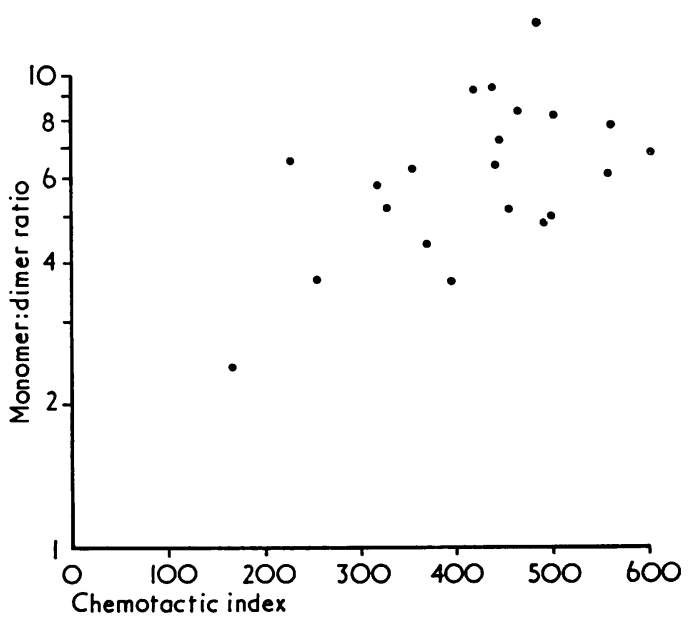

FIG. 5 Correlation between neutrophil chemotaxis index and monomer:dimer ratio. Correlation coefficient $=$ $0.462 ; \mathrm{P}<0.05$ 
The chemotactic index was inversely correlated with the percentage inhibition of $K$ cell mediated cytotoxicity but not at conventional levels of significance $(0 \cdot 1<\mathbf{P}<0 \cdot 2)$.

\section{SERUM PROTEINS AND CLINICAL CORRELATION}

No significant correlation was observed between the serum protein levels and the IgG commencement and monomer: dimer ratio. In addition no significant correlation was seen between the results of the two assays for complexes and the clinical activity, duration of morning stiffness, or the haematological and biochemical measurements used in the assessment of rheumatoid arthritis.

\section{Discussion}

Two methods have been used for the detection of complexes in sera, the inhibition of $\mathrm{K}$ cell mediated cytotoxicity, and the physical separation of serum proteins by molecular size. Preformed soluble immune complexes in antigen antibody equilibrium or slight antigenic excess are known to optimally inhibit $\mathrm{K}$ cell induced cytolysis to sensitized Chang target cells, a continuous human liver cell line (MacLennan, 1972). The $\mathrm{K}$ cells active in this assay have the morphological appearance of small lymphocytes but they do not possess the standard characteristics of $T$ or $B$ cells.

Inhibitory material eluting between IgG and IgM on gel filtration with the characteristics of immune complexes has been described using this method in sera of patients with inflammatory bowel disease (Jewell and MacLennan, 1973) and in rheumatoid arthritis (Barnett and MacLennan, 1972). Hallberg (1972) using chicken erythrocytes as his target cells also showed enhanced inhibition in 21 seropositive rheumatoid sera compared with 17 blood donor controls. In both rheumatoid studies there was no correlation between inhibitory activity and the rheumatoid titre.

In this study the significant correlation seen between inhibition of $K$ cell cytotoxicity and the monomer: dimer ratio obtained from the results of gel filtration of sera provides positive, if indirect, evidence that $\mathbf{K}$ cell-induced cytolysis of sensitized target cells is inhibited by these IgG-containing complexes eluting between the IgG and IgM markers. It must be noted, however, that inhibition of $K$ cell-induced cytolysis may also occur due to antiHLA antibody directed against tissue antigens on the effector cell (Hersey, Cullen, and MacLennan, 1973) and to nonimmunoglobulin factors as illustrated by the finding that different batches of fetai bovine serum which contain little or no immunoglobulin will permit somewhat different degrees of cytolysis. Thus, this method is at best a screening test for detecting circulating immune complexes.

The second assay involved gel chromatography of sera on Sepharose 6B. The results show that the sera from the majority of patients with rheumatoid arthritis contain IgG emerging in higher molecular size fractions than that from the healthy controls. In some patients IgG eluted in the region of the IgM marker. It is thought that this could indicate that the origin was from the dissociating IgM-IgG '22S' complex which is known to occur in rheumatoid arthritis (Franklin and others, 1957). IgG commencement in this study did not correlate with the latex titre, but it is not known if this titre correlates with the presence of a '22S' complex as seen on analytical ultracentrifugation.

The observations in this study are similar to the findings of Norberg (1974) who examined sera from 33 seropositive patients with rheumatoid arthritis by sedimentation analysis and gel filtration. Complexes were detected as a continuum from the $7 \mathrm{~S}$ to the $19 \mathrm{~S}$ region in 23 sera $(70 \%)$. Similarly, Winchester and Kunkel (1968), using monoclonal IgM rheumatoid factor to precipitate complexes, found positive precipitation reactions in $57 \%$ of sera from rheumatoid patients. However, it has been suggested that IgM rheumatoid factor map not precipitate with very small complexes (RoNorberg, unpublished observations; Norberg, 1974) Norberg (1974) noted that there was a higher frequency of detected complexes in rheumatoid sera when the rheumatoid factor titre was equal to or greater than 1:1280 compared to those less seropositive ( $80 \%$ compared with $54 \%$ respectively).

No significant correlation could be made between the quantity of complex and the age, duration of disease, or clinical activity of the patients in this study or with the laboratory parameters. However, a significant inverse correlation was observed between the chemotactic index of the circulating neutrophils from the rheumatoid patients and the amount of immune complexes detected in the serum. These results confirm the earlier suggestion of Mowat and Baum (1971) that the impairment in neutrophil chemotaxis in patients with rheumatoid arthritis could be related to the prior ingestion of immune complexes.

Normal neutrophil chemotactic activity is essential for the control of bacterial infection. There is some evidence for increased bacterial infection rates during life and especially as a cause of death in patients with rheumatoid arthritis. The quantitation of these small circulating complexes or the measurement of the chemotactic index may thus have important clinical significance.

The nature of the small IgG-containing intermediate complexes, their aetiology and their relationship to the pathogenesis of the disease in 
which they occur is obscure. The intermediate complexes seen in rheumatoid arthritis and hypergammaglobulinaemic purpura of Waldenström can be dissociated to yield monomeric 7S IgG (Kunkel and others, 1961; Norberg, 1974). Other evidence, especially in the rheumatic diseases, suggests that IgG rheumatoid factor is a component of these complexes (Capra, Winchester, and Kunkel, 1971; Schroenloher, 1966). Pope and his colleagues (1975) have suggested that the intermediate complexes may be formed by self-association of IgG-rheumatoid factors.

The continued persistence in the circulation of small intermediate complexes in rheumatoid arthritis and other diseases indicates a dynamic equilibrium between loss and production. This would be unusual for classical immune complexes unless one postulates that balanced synthesis of antibody occurs to maintain a steady antigen-to-antibody ratio. However, an explanation for the persistence of these intermediate complexes in rheumatoid arthritis sera may accrue from the presence in the complex of small, e.g. polypeptide-sized, molecules with one or two antigenic determinants where a three-dimensional lattice could not be formed. Hence the size of the complex would be small and would tend to persist (Mannik and Arend, 1971). If this is the case, detection of the antigen would be difficult and this might explain the absence of an antigen after dissociation of the complex. Rheumatoid factors might, therefore, be adaptive mechanisms to aid clearance from the circulation of complexes by increasing lattice formation and thereby size.

P. J. R-T. is the recipient of the Brasenose College Senior Hulme (Overseas) Scholarship. We would like to sincerely thank Mrs. A. Houghton for typing the script, Dr. S. E. Barnes for reading the script, and Miss S. Howard for help in statistical analysis of the results.

\section{References}

Alarcon-Segovia, D., Fishbein, E., Abruzzo, J. L., And Heimer, R. (1974) Ann. intern. Med., 80, 35 (Serum hyperviscosity in Sjögren's syndrome)

BaRnett, I. G., AND MACLENNAN, I. C. M. (1972) Ann. rheum. Dis., 31, 425 (Inhibitory effect of rheumatoid sera on cell damage by lymphocytes)

Baum, J., Mowat, A. G., AND KIRK, J. A. (1971) J. Lab. clin. Med., 77, 501 (A simplified method for the measurement of chemotaxis of polymorphonuclear leucocytes from human blood)

BenACERRAF, B., SEBESTYEN, M., AND COOPER, N. S. (1959) J. Immunol., 82, 131 (The clearance of antigen-antibody complexes from the blood by reticulo-endothelial system)

Blaylock, W. M., Waller, M., and Normansell, D. E. (1974) Ann. intern. Med., 80, 27 (Sjögren's syndrome: hyperviscosity and intermediate complexes)

Calder, E. A., Penhale, W. J., Barnes, E. W., AND Irvine, W. J. (1974) Brit. med. J., 2, 30 (Evidence for circulating immune complexes in thyroid disease)

CAMP, A. V. (1971) Orthopaedics, 4, 39 (An articular index for the assessment of rheumatoid arthritis)

CAPRA, J. D., WinCHESTER, R. J., AND KUNKel, H. G. (1971) Medicine, 50, 125 (Hypergammaglobulinaemic purpura: studies on the unusual anti- $\gamma$ globulins characteristic of the sera of these patients)

Franklin, E. C., Müller-Eberhard, H. J., Holman, H., and Kunkel, H. G. (1957) J. exp. Med., 105, 425 (An unusual protein component of high molecular weight in the serum of certain patients with rheumatoid arthritis)

GoтcH, F. M. (1973) The role of immunoglobulin in phagocytosis. MSc thesis, Oxford University.

HALLBERG, T. (1972) Scand. J. Immunol., 1, 329 (In vitro cytotoxicity of human lymphocytes for sensitized chicken erythrocytes is inhibited by sera from rheumatoid arthritis patients)

Hersey, P., Cullen, P., AND Maclennan, I. C. M. (1973) Transplantation, 16, 9 (Lymphocyte-dependent cytotoxic activity against human transplantation antigens)

Jewell, D. P., AND MaCLennan, I. C. M. (1973) Clin. exp. Immunol., 14, 219 (Circulating immune complexes in inflammatory bowel disease)

Kunkel, H. G., Müller-Everhard, H. J., Fudenberg, H. H., AND Tomasi, T. B. (1961) J. clin. Invest., 40, 117 (Gamma-globulin complexes in rheumatoid arthritis and certain other conditions)

MaCLennan, I. C. M. (1972) Clin. exp. Immunol., 10, 275 (Competition for receptors for immunoglobulin on cytotoxic lymphocytes)

- LOEWI, G., AND HOWARD, A. (1969) Immunology, 17, 887 (A human serum immunoglobulin with specificity for certain homologous target cells which induces target cell damage by normal human lymphocytes)

Mancini, G., Carbonara, A. O., ANd Heremans, J. F. (1965) Immunochemistry, 2, 235 (Immunochemical quantitation of antigens by single radial immunodiffusion)

MANNIK, M., AND AREND, W. P. (1971) J. exp. Med., 134, 195 (Fate of preformed immune complexes in rabbits and rhesus monkeys)

Mowat, A. G., AND BAUM, J. (1971) J. clin. Invest., 50, 2541 (Chemotaxis of polymorphonuclear leucocytes from patients with rheumatoid arthritis) 
NORBERG, R. (1974) Scand. J. Immunol., 3, 229 (IgG complexes in serum of rheumatoid arthritis patients)

Pope, R. M., Mannik, M., Gilliland, B. C., AND Teller, D. C. (1975) Arthr. and Rheum., 18, 97 (The hyperviscosity syndrome in rheumatoid arthritis due to intermediate complexes formed by self-association of IgG-rheumatoid factor)

SCHROENLOHER, R. A. (1966) J. clin. Invest., 45, 501 (Characterization of the globulin complexes present in certain sera having high titres of antiglobulin activity)

WINCHESTER, R. J., AND KUNKEL, H. G. (1968) Arthr. and Rheum., 11, 849 (High molecular weight complexes involving gammaglobulin in joint fluids from rheumatoid arthritis patients)

, - - AND AGNello, V. (1971) J. exp. Med., 134, 2865 (Occurrence of gammaglobulin complexes in serum and joint fluids of rheumatoid arthritis patients. Use of monoclonal rheumatoid factors as reagents for their demonstration) 